\title{
Elastic Properties, Mechanical Stability, and State Densities of Aluminnides
}

\author{
B.R. ZHANG ${ }^{a}$, Z. JiA ${ }^{a}$, X.Z. DUAN ${ }^{b, *}$ AND X.Z. YANG ${ }^{a}$ \\ ${ }^{a}$ Aviation General Hospital, Beijing, 100012, China \\ ${ }^{b}$ Beijing Tongren Hospital, Beijing, 100730, China \\ (Received July 22, 2012; in final form February 9, 2013)
}

\begin{abstract}
First-principles calculations were performed to study on alloying stability, electronic structure, and mechanical properties of Al-based intermetallic compounds. The results show that the lattice parameters obtained after full relaxation of crystalline cells are consistent with experimental data. The calculation of cohesive energies indicated that the structure stability of these Al-based intermetallics will become higher with increasing $\mathrm{Zr}$ element in crystal. The calculations of formation energies showed that $\mathrm{AlCu}_{2} \mathrm{Zr}$ has the strongest alloying ability, followed by $\mathrm{AlZr}_{3}$ and finally the $\mathrm{AlCu}_{3}$. Further analysis finds out that single-crystal elastic constants at zero-pressure satisfy the requirement of mechanical stability for cubic crystals. The calculations on the ratio of bulk modulus to shear modulus reveal that $\mathrm{AlCu}_{2} \mathrm{Zr}$ can exhibit a good ductility, followed by $\mathrm{AlCu}_{3}$, whereas $\mathrm{AlZr}_{3}$ can have a poor ductility; however, for stiffness, these intermetallics show a converse order. The calculations on Poisson's ratio show that $\mathrm{AlCu}_{3}$ is much more anisotropic than the other two intermetallics. In addition, calculations on densities of states indicates that the valence bonds of these intermetallics are attributed to the valence electrons of $\mathrm{Cu} 3 d$ states for $\mathrm{AlCu}_{3}, \mathrm{Cu} 3 d$ and $\mathrm{Zr} 4 d$ states for $\mathrm{AlCu}_{2} \mathrm{Zr}$, and $\mathrm{Al} 3 s, \mathrm{Zr} 5 s$ and $4 d$ states for $\mathrm{AlZr}_{3}$, respectively; in particular, the electronic structure of the $\mathrm{AlZr}_{3}$ shows the strongest hybridization, leading to the worst ductility.
\end{abstract}

DOI: 10.12693 /APhysPolA.123.668

PACS: 31.15.A-

\section{Introduction}

Aluminum alloys represent an important category of materials because of their high technological value and their wide application, especially, in the aerospace field, microelectronics, motorized vehicles, and domestic industry. Due to the importance of the alloys in engineering and the basic research, mechanical behavior of the alloys has been a focus of various investigations. In particular, the strengthening for the alloys has attracted strong interest from both academic and industrial aspects. Over the past decades, various strengthening methods have been developed, e.g., alloying, and can solve the proposed issue. However, for other properties, such as corrosion or thermal resistance, such effectiveness is limit. Instead of the (micro amount) alloying method, a large amount of alloy elements can be used to form the so-called Al-based intermetallic compounds. It is found that such intermetallics can exhibit various excellent properties, including mechanical, physical, and chemical ones, because bonding nature or electronic structure are changed [1].

Intermetallics involving aluminum and transition metals (TM) are known to have high resistance to oxidation and corrosion, elevated-temperature strength, relatively low density, and high melting points, which making them desirable candidates for high-temperature structural applications [2]. In particular, zirconium can effectively enhance the mechanical strength of the alloys when copper and zinc elements exist in aluminum and Al-based alloys [3]. Adding $\mathrm{Zr}$ in the $\mathrm{Al}-\mathrm{Mg}$ alloys can effectively

*corresponding author discard hydrogen, grain refinement, reducing pinholes, porosity and hot cracking tendency and improve its mechanical properties [4]. Many investigations have been focused on the constituent binary systems, such as $\mathrm{Al}-\mathrm{Cu}$, $\mathrm{Al}-\mathrm{Zr}$, and $\mathrm{Cu}-\mathrm{Zr}$ [5-10], however, there has been a lack of systematic theoretical and experimental investigations for binary and ternary system, especially for ternary alloy system.

In recent years, first-principles calculations based on the density-functional theory have become an important tool for the accurate study of the crystalline and electronic structures and mechanical properties of solids [11]. In the present study, we report a systematic investigation of the structural, elastic and electronic properties of Al-based alloys $\left(\mathrm{AlCu}_{3}, \mathrm{AlZr}_{3}\right.$, and $\left.\mathrm{AlCu}_{2} \mathrm{Zr}\right)$ by first-principles calculations, and the results are discussed in comparison with the available experimental data and other theoretical results.

\section{Computational method}

All calculations were performed using the Vienna $a b$ initio Simulation Package (VASP) $[12,13]$ based on the density-functional theory (DFT) [14]. The exchange and correlation energy was treated within the generalized gradient approximation of Perdew-Wang 91 version (GGA-PW91) [15]. The interaction between the valence electrons and the ions was described by using potentials generated with Blöchl's projector augmented wave (PAW) method [16]. The PAW potential used for Al treats $3 s$, $3 p$ states as valence states, and the other electron-ion interaction was described by $3 d, 4 s$ valence states for $\mathrm{Cu}, 5 s, 4 d, 5 p$ valence states for $\mathrm{Zr}$. A plane-wave energy cutoff was set at $450 \mathrm{eV}$ for $\mathrm{AlCu}_{3}$ and $\mathrm{AlCu}_{2} \mathrm{Zr}$, and at $350 \mathrm{eV}$ for $\mathrm{AlZr}_{3}$. The Brillouin zone integrations 
were performed using the Monkhorst-Pack [17] $k$-point meshes, e.g., the $k$-point meshes for $\mathrm{AlCu}_{3}, \mathrm{AlCu}_{2} \mathrm{Zr}$ and $\mathrm{AlZr}_{3}$ were $15 \times 15 \times 15,9 \times 9 \times 9$ and $13 \times 13 \times 13$ for optimizing geometry and calculating elastic constants, and $25 \times 25 \times 25,19 \times 19 \times 19$ and $23 \times 23 \times 23$ for the calculations of density of states (DOS) at the equilibrium volume, respectively.

Optimizations of the structural parameters (atomic positions and the lattice constants) for each system were performed using the conjugate gradient method, and the coordinates of internal atoms were allowed to relax until the total forces on each ion were less than $0.01 \mathrm{eV} / \AA$. The total energy and density of states (DOS) calculations were performed with the linear tetrahedron method with the Blöchl corrections [18]. In order to avoid wrap-around errors, all calculations were performed using the "accurate" setting within VASP.

\section{Results and discussion}

\subsection{Equilibrium properties}

$\mathrm{AlCu}_{3}$ and $\mathrm{AlZr}_{3}$ alloys have the simple cubic $\mathrm{Cu}_{3} \mathrm{Au}$ ( $L 1_{2}$ type, space group $P m-3 m$ ) structure [19, 20], $\mathrm{AlCu}_{2} \mathrm{Zr}$ crystallizes in cubic symmetry with the space group $F m-3 m$ [21]. Firstly, these crystal structures were optimized with relaxation of cell shape and atomic positions. The equilibrium volume $V_{0}$, bulk modulus $B_{0}$ and the pressure derivation of bulk modulus $B_{0}^{\prime}$ of $\mathrm{AlCu}_{3}$, $\mathrm{AlCu}_{2} \mathrm{Zr}$, and $\mathrm{AlZr}_{3}$ were determined by fitting the total energy calculated at different lattice constant values to a Birch-Murnaghan equation of state [22]. The results of first-principles calculations are listed in Table I. From Table I, one can see that the results of our calculations compare very favorably with experimental data. This shows that the used parameters are reasonable.

TABLE I

Calculated and experimental lattice parameters $a(\AA)$, equilibrium volume $V_{0}\left(\AA^{3}\right)$, bulk modulus $B_{0}(\mathrm{GPa})$ and the pressure derivation of bulk modulus $B_{0}^{\prime}$ for $\mathrm{AlCu}_{3}$, $\mathrm{AlCu}_{2} \mathrm{Zr}, \mathrm{AlZr}_{3}$.

\begin{tabular}{c|c|c|c|c|c|c}
\hline \hline & \multicolumn{2}{|c|}{$\mathrm{AlCu}_{3}$} & \multicolumn{2}{c|}{$\mathrm{AlCu}_{2} \mathrm{Zr}$} & \multicolumn{2}{c}{$\mathrm{AlZr}_{3}$} \\
\cline { 2 - 7 } & present & exp. & present & exp. & present & exp. \\
\hline$a$ & 3.693 & $3.607[19]$ & 6.256 & $6.216[21]$ & 4.381 & $4.392[20]$ \\
$V_{0}$ & 50.358 & - & 244.805 & $240.210[21]$ & 84.110 & $84.700[20]$ \\
$B_{0}$ & 131.010 & - & 128.600 & - & 100.800 & \\
$B_{0}^{\prime}$ & 4.47 & - & 4.280 & - & 3.48 &
\end{tabular}

It is known that the stability of crystal structure is correlated to its cohesive energy [23], which is often defined as the work which is needed when crystal is decomposed into the single atom. Hence, the bigger the cohesive energy is, the more stable the crystal structure is [23]. In the present study, the cohesive energies $\left(E_{\mathrm{coh}}\right)$ of $\mathrm{AlCu}_{3}$, $\mathrm{AlCu}_{2} \mathrm{Zr}$ and $\mathrm{AlZr}_{3}$ crystal cells can be calculated by

$$
\begin{aligned}
& E_{\mathrm{coh}}^{\mathrm{ABC}}=\left(E_{\text {tot }}-N_{\mathrm{A}} E_{\text {atom }}^{\mathrm{A}}-N_{\mathrm{B}} E_{\text {atom }}^{\mathrm{B}}-N_{\mathrm{C}} E_{\text {atom }}^{\mathrm{C}}\right) \\
& \quad /\left(N_{\mathrm{A}}+N_{\mathrm{B}}+N_{\mathrm{C}}\right)
\end{aligned}
$$

where $E_{\text {tot }}$ is the total energy of the compound at the equilibrium lattice constant, and $E_{\text {atom }}^{\mathrm{A}}, E_{\text {atom }}^{\mathrm{B}}, E_{\text {atom }}^{\mathrm{C}}$ are the energies of the isolated atoms $\mathrm{A}, \mathrm{B}$, and $\mathrm{C}$ in the freedom states. $N_{\mathrm{A}}, N_{\mathrm{B}}$, and $N_{\mathrm{C}}$ refer to the numbers of $\mathrm{A}, \mathrm{B}$, and $\mathrm{C}$ atoms in each unit cell. The energies of isolated $\mathrm{Al}, \mathrm{Cu}$, and $\mathrm{Zr}$ atoms are $-0.276 \mathrm{eV}$, $-0.254 \mathrm{eV}$ and $-2.054 \mathrm{eV}$, respectively. Cohesive energies $\left(E_{\mathrm{coh}}\right)$ per atom of all crystal or primitive cells are calculated from Eq. (1). It was found for Al-based intermetallic compounds that the cohesive energy $\left(E_{\mathrm{coh}}\right)$ of per atom for $\mathrm{AlCu}_{3}, \mathrm{AlCu}_{2} \mathrm{Zr}$ and $\mathrm{AlZr}_{3}$ are $-3.637 \mathrm{eV}$, $-4.551 \mathrm{eV},-5.964 \mathrm{eV}$, respectively. These results are listed in Table II. Based on the above results, it can be concluded that the cohesive energy of these Al-based intermetallic compounds will become lower with increasing $\mathrm{Zr}$ element in crystal, hence the stability of crystal increases. Therefore, the $\mathrm{AlZr}_{3}$ intermetallic compound should have the highest structure stability, followed by $\mathrm{AlCu}_{2} \mathrm{Zr}$ and finally the $\mathrm{AlCu}_{3}$.

\section{TABLE II}

Total energy $E_{\text {tot }}$, cohesive energy $E_{\text {coh }}$ and formation energy $\Delta H$ of $\mathrm{AlCu}_{3}, \mathrm{AlCu}_{2} \mathrm{Zr}$, and $\mathrm{AlZr}_{3}$.

\begin{tabular}{c|c|c|c}
\hline \hline Compound & $\begin{array}{c}E_{\text {tot }} \\
\text { [eV/atom] }\end{array}$ & $\begin{array}{c}E_{\text {coh }} \\
{[\mathrm{eV} / \text { atom }]}\end{array}$ & $\begin{array}{c}\Delta H \\
{[\mathrm{eV} / \text { atom }]}\end{array}$ \\
\hline $\mathrm{AlCu}_{3}$ & -3.897 & -3.637 & -0.177 \\
$\mathrm{AlCu}_{2} \mathrm{Zr}$ & -5.261 & -4.551 & -0.359 \\
$\mathrm{AlZr}_{3}$ & -7.574 & -5.964 & -0.307
\end{tabular}

In order to compare the alloying abilities of the present compounds, we calculate the formation energy $\Delta H$, which can be given by

$$
\begin{aligned}
& \Delta H_{\mathrm{ABC}}=\left(E_{\mathrm{tot}}-N_{\mathrm{A}} E_{\mathrm{solid}}^{\mathrm{A}}-N_{\mathrm{B}} E_{\mathrm{solid}}^{\mathrm{B}}-N_{\mathrm{C}} E_{\mathrm{solid}}^{\mathrm{C}}\right) \\
& \quad /\left(N_{\mathrm{A}}+N_{\mathrm{B}}+N_{\mathrm{C}}\right),
\end{aligned}
$$

where $E_{\text {solid }}^{\mathrm{A}}, E_{\text {solid }}^{\mathrm{B}}$, and $E_{\text {solid }}^{\mathrm{C}}$ are the energies per atom of pure constituents $\mathrm{A}, \mathrm{B}$, and $\mathrm{C}$ in the solid states, respectively. The other variables are as defined for Eq. (1). Negative formation energies usually indicate an exothermic process. Furthermore, the bigger the formation energy is, the stronger alloying ability is [23]. The calculated energies of $\mathrm{Al}, \mathrm{Cu}$, and $\mathrm{Zr}$ in their respective crystals are $-3.696 \mathrm{eV},-3.728 \mathrm{eV},-8.457 \mathrm{eV}$. The calculated results of these compounds are also listed in Table II. The formation energies of $\mathrm{AlCu}_{3}, \mathrm{AlCu}_{2} \mathrm{Zr}$ and $\mathrm{AlZr}_{3}$ are all negative, which means that the structure of these phases can exist and be stable. The present results also indicate that $\mathrm{AlCu}_{2} \mathrm{Zr}$ phase has the biggest formation energies, suggesting a strong alloying ability. It should be noted that the formation energies of $\mathrm{AlZr}_{3}$ was larger than that of $\mathrm{AlCu}_{3}$, indicating that the latter has a weaker alloying ability than the former. Here, cohesive energy and formation energies expected different trends in stability. Due to the higher cohesive energy of $\mathrm{Zr}$, the cohesive energy of the alloys increases when the $\mathrm{Zr}$ content increases.

\subsection{Mechanical properties}

The density-functional theory has become a powerful tool for investigating the elastic properties of materials (in the limit of zero temperature and in the absence of zero-point motion). For a given crystal it is possible to calculate the complete set of elastic constants by apply- 
ing small strains to the equilibrium unit cell and determining the corresponding variations in the total energy. The necessary number of strains is imposed by the crystal symmetry [24]. For a material with cubic symmetry, there are only three independent elastic constants, $C_{11}$, $C_{12}$, and $C_{44}$. The strain tensor is given by

$$
\delta=\left(\begin{array}{lll}
\delta_{11} & \delta_{12} & \delta_{13} \\
\delta_{21} & \delta_{22} & \delta_{23} \\
\delta_{31} & \delta_{32} & \delta_{33}
\end{array}\right)
$$

In the present study, we applied three kinds of strains $\delta^{(\mathrm{N})}(N=1,2,3)$ so as to obtain the elastic constants, and they are listed in Table III. The first strain is a volume-conserving tetragonal deformation along the $z$ axis, the second refers to a uniform hydrostatic pressure, and the last one corresponds to a volume-conserving orthorhombic shear [24]. The elastic strain energy was given by

$$
U=\frac{\Delta E}{V_{0}}=\frac{1}{2} \sum_{i=1}^{6} \sum_{j=1}^{6} C_{i j} e_{i} e_{j}
$$

where $\Delta E=E_{\text {total }}\left(V_{0}, \delta\right)-E_{\text {total }}\left(V_{0}, 0\right)$ is the total energy variation between the deformed cell and the initial cell, $V_{0}$ is the equilibrium volume of the cell, $C_{i j}$ are the elastic constants and $\delta$ is the deformation added to the equilibrium cell. The elastic strain energy is also listed in Table III. For each kind of lattice deformation, the total energy has been calculated for different strains $\gamma= \pm 0.01 n(n=0-2)$.

\section{TABLE III}

The strains used to calculate the elastic constants of $\mathrm{AlCu}_{3}$, $\mathrm{AlCu}_{2} \mathrm{Zr}$, and $\mathrm{AlZr}_{3}$, with $\gamma= \pm 0.01 n(n=0-2)$.

\begin{tabular}{c|c|c}
\hline \hline Strain & Parameters (unlisted $\left.\delta_{i j}=0\right)$ & $\Delta E / V_{0}$ to $\mathrm{O}\left(\gamma^{2}\right)$ \\
\hline$\delta^{(1)}$ & $\delta_{11}=\delta_{22}=\gamma, \delta_{33}=\left[(1+\gamma)^{-2}-1\right]$ & $3\left(C_{11}-C_{12}\right) \gamma^{2}$ \\
$\delta^{(2)}$ & $\delta_{11}=\delta_{22}=\delta_{33}=\gamma$ & $\frac{3}{2}\left(C_{11}+2 C_{12}\right) \gamma^{2}$ \\
$\delta^{(3)}$ & $\delta_{12}=\delta_{21}=\gamma, \delta_{33}=\left[\gamma^{2}\left(1-\gamma^{2}\right)^{-1}\right]$ & $2 C_{44} \gamma^{2}$
\end{tabular}

By means of polynomial fit, we extracted three values of the second order coefficients, corresponding to $3\left(C_{11}-C_{12}\right), 3\left(C_{11}+2 C_{12}\right) / 2$ and $2 C_{44}$, respectively, the elastic constants $C_{11}, C_{12}$, and $C_{44}$ were obtained [25], and the results are showed in Table IV. From Table IV, we can see that our calculation results agree well with the experimental data or other first-principle calculations. These elastic constants satisfy the requirement of mechanical stability for cubic crystals [24]: $\left(C_{11}-C_{12}\right)>0$, $C_{11}>0, C_{44}>0,\left(C_{11}+2 C_{12}\right)>0$. This shows that $\mathrm{AlCu}_{3}, \mathrm{AlCu}_{2} \mathrm{Zr}$, and $\mathrm{AlZr}_{3}$ have a stable structure. The average bulk modulus is identical to the single-crystal bulk modulus, i.e., $B=\left(C_{11}+2 C_{12}\right) / 3$. Interestingly, we noted that the bulk modulus calculated from the values of the elastic constants is in good agreement with the one obtained through the fit to a Birch-Murnaghan equation of state $\left(B_{0}\right)$, giving a consistent estimation of the compressibility for these compounds [26].

TABLE IV

Calculated elastic constants (GPa) and elastic modulus (bulk modulus $B$ (GPa), shear modulus $G(\mathrm{GPa}$ ), Young's modulus $E(\mathrm{GPa})$, Poisson's ratio $\nu$ and anisotropy constant $A$ ) of $\mathrm{AlCu}_{3}, \mathrm{AlCu}_{2} \mathrm{Zr}$, and $\mathrm{AlZr}_{3}$.

\begin{tabular}{c|c|c|c|c|c|c|c|c|c|c}
\hline \hline Compound & $C_{11}$ & $C_{12}$ & $C_{44}$ & $B$ & $G$ & $B / G$ & $E$ & $\nu$ & $A$ & Ref. \\
\hline $\mathrm{AlCu}_{3}$ & 150.707 & 120.565 & 81.880 & 130.612 & 43.593 & 2.996 & 117.686 & 0.350 & 1.887 & this study \\
& 176.000 & 117.400 & 92.400 & 136.900 & 49.600 & & 132.800 & 0.340 & & {$[5]$} \\
$\mathrm{AlCu}_{2} \mathrm{Zr}$ & 157.504 & 115.305 & 62.685 & 129.371 & 41.237 & 3.137 & 111.829 & 0.356 & 1.528 & this study \\
$\mathrm{AlZr}_{3}$ & 148.653 & 79.387 & 70.834 & 102.476 & 53.400 & 1.919 & 136.492 & 0.278 & 1.487 & this study \\
& 163.800 & 79.300 & 86.500 & 107.670 & & & & & \multicolumn{2}{c}{ [6] }
\end{tabular}

In order to further validate our results, the elastic modulus, such as shear modulus $G(\mathrm{GPa})$, Young's modulus $E(\mathrm{GPa})$, Poisson's ratio $\nu$ and anisotropy constant $A$ for a polycrystalline material were also calculated with the single-crystal elastic constants $C_{i j}$, all of these elastic modulus are shown in Table IV. In the present study, we adopted Hershey's averaging method [27], which has been known to give the most accurate relation between single-crystal and polycrystalline values for a cubic lattice [28]. According to this method, $G$ is obtained by solving the following equation:

$$
\begin{gathered}
G^{3}+\frac{5 C_{11}+4 C_{12}}{8} G^{2}-\frac{C_{44}\left(7 C_{11}-4 C_{12}\right)}{8} G \\
-\frac{C_{44}\left(C_{11}-C_{12}\right)\left(C_{11}+2 C_{12}\right)}{8}=0 .
\end{gathered}
$$

The calculated shear modulus $G$ for the $\mathrm{AlZr}_{3}$ are the largest, while the quantities for $\mathrm{AlCu}_{2} \mathrm{Zr}$ are less than for $\mathrm{AlCu}_{3}$.

Pugh [29] found that the ratio of the bulk modulus to shear modulus $(B / G)$ of polycrystalline phases can predict the brittle and ductile behavior of materials. A high and low value of $B / G$ are associated with ductility and brittleness, respectively. The critical value which separates ductility from brittleness is about 1.75 . From $B / G$ calculated in Table IV we can see that all the $B / G$ ratios are larger than 1.75. Therefore, $\mathrm{AlCu}_{3}, \mathrm{AlCu}_{2} \mathrm{Zr}$ and $\mathrm{AlZr}_{3}$ have a good ductility. On the contrary, the biggest $B / G$ ratio for $\mathrm{AlCu}_{2} \mathrm{Zr}$ indicates that $\mathrm{AlCu}_{2} \mathrm{Zr}$ is of very good ductility in these three Al-based alloys. $\mathrm{AlCu}_{3}$ has an intermediate ductility, while $\mathrm{AlZr}_{3}$ has a worst ductility. 
Besides $B / G$, Young's modulus $E$ and Poisson's ratio $\nu$, are important for technological and engineering applications. Young's modulus is used to provide a measure of the stiffness of the solid, i.e., the larger the value of $E$, the stiffer the material [24]. According to Hershey's averaging method, Young's modulus is defined as: $E=9 G B /(3 B+G)$. Based on the calculated results, we find that $\mathrm{AlZr}_{3}$ has a Young modulus that is 18.806 $\mathrm{GPa}$ and 24.663 $\mathrm{GPa}$ larger than for $\mathrm{AlCu}_{3}$ and $\mathrm{AlCu}_{2} \mathrm{Zr}$, respectively. This indicates that $\mathrm{AlZr}_{3}$ phase has the highest stiffness, followed by $\mathrm{AlCu}_{3}$ and finally the $\mathrm{AlCu}_{2} \mathrm{Zr}$. In addition, Poisson's ratio $\nu$ has also been used to measure the shear stability of the lattice, which usually ranges from -1 to 0.5 . The greater the value of Poisson's ratio $\nu$, the better the plasticity of the materials. So we can see that $\mathrm{AlCu}_{3}, \mathrm{AlCu}_{2} \mathrm{Zr}$ and $\mathrm{AlZr}_{3}$ have a better plasticity.

The elastic anisotropy of crystals has an important application in engineering materials since it is highly correlated with the possibility of inducing microcracks $[24,30]$. For cubic symmetric structures [31], the elastic anisotropy is defined as $A=\left(2 C_{44}+C_{12}\right) / C_{11}$. For the completely isotropic material, the value of $A$ will be 1 , while values smaller or bigger than 1 measuring the degree of elastic anisotropy [24]. Interestingly, we note that the values of $A$ (Table IV) do not deviate far from unity, suggesting that the present cubic structure alloys also do not deviate far from being isotropic. The calculated results also indicate that $\mathrm{AlCu}_{3}$ is much more anisotropic than the other two alloys.

\subsection{Density of the states}

For further understanding of the electronic characteristics and structural stability, total density of states (DOS) of $\mathrm{AlCu}_{3}, \mathrm{AlCu}_{2} \mathrm{Zr}$ and $\mathrm{AlZr}_{3}$ were calculated, as shown in Fig. 1, as well as the partial density of states (PDOS) of $\mathrm{Al}, \mathrm{Cu}$ and $\mathrm{Zr}$ atoms in these Al-based intermetallics compounds. In Figure 1 there is evident the metallic character of these considered $\mathrm{AlCu}_{3}, \mathrm{AlCu}_{2} \mathrm{Zr}$, and $\mathrm{AlZr}_{3}$ structure because of the finite DOS at the Fermi level. With regard to the total density of states curve of $\mathrm{AlCu}_{3}$, one can see from Fig. 1a that the whole valence band of $\mathrm{AlCu}_{3}$ is located between $-7 \mathrm{eV}$ and $9 \mathrm{eV}$, which is dominated by $\mathrm{Cu} 3 d$ states and a small contribution from $3 s$ and $3 p$ states of $\mathrm{Al}$. The valence band of $\mathrm{AlZr}_{3}$ (see Fig. 1c) can be divided into three areas. The first area dominated by the valence electron numbers of $\mathrm{Al} 3 \mathrm{~s}$ and $\mathrm{Zr} 4 d$ states are mostly located between $-7 \mathrm{eV}$ and $-5 \mathrm{eV}$, the second by the $\mathrm{Zr} 5 s$ and $4 d$ states located between $-4 \mathrm{eV}$ and $-3 \mathrm{eV}$, and the third by $\mathrm{Zr} 4 d$ states located between $-2.8 \mathrm{eV}$ and $3.0 \mathrm{eV}$. Both below and above the Fermi level, the hybridization between $\mathrm{Al} p$ states and Zr $d$ states is strong. Due to the strong hybridization (or covalent interaction) the entire DOS can be divided into bonding and antibonding regions, and that a pseudogap resides in between. The characteristic pseudogap around the Fermi level indicates the presence of the directional covalent bonding.

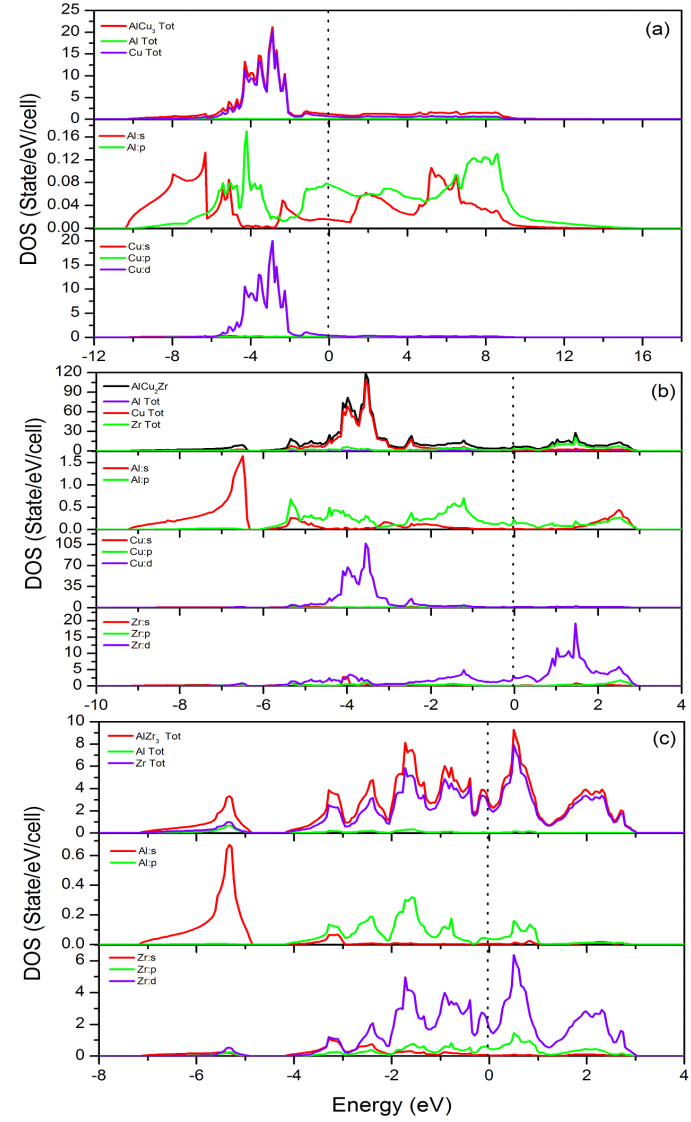

Fig. 1. The total and partial DOS of $\mathrm{AlCu}_{3}$ crystal cell (a), $\mathrm{AlCu}_{2} \mathrm{Zr}$ crystal cell (b), $\mathrm{AlZr}_{3}$ crystal cell (c). The vertical dot line indicates the Fermi level.

The Fermi level located at a valley in the bonding region implies the system has a pronounced stability. It is also generally considered that the formation of covalent bonding would enhance the strength of material in comparison with the pure metallic bonding [32]. According to the covalent approach, the guiding principle is the maximize bonding. Therefore, for a series of compounds having the same structure, the greater the occupancy in the bonding region the higher the stability [33]. It is indeed seen that the structural stability increases from $\mathrm{AlCu}_{3}$ to $\mathrm{AlZr}_{3}$. For $\mathrm{AlCu}_{2} \mathrm{Zr}$ (see Fig. 1b), it is found that the main bonding peaks between $-6 \mathrm{eV}$ and $-2 \mathrm{eV}$ are predominantly derived from the $\mathrm{Cu} 3 d$ orbits, while the main bonding peaks between the Fermi level and $3 \mathrm{eV}$ predominantly derived from the $\mathrm{Zr} 4 d$ orbits. It should be noted that the phase stability of intermetallics depends on the location of the Fermi level and the value of the DOS at the Fermi level, i.e. $N\left(E_{\mathrm{F}}\right)[34,35]$. A lower $N\left(E_{\mathrm{F}}\right)$ corresponds to a more stable structure. The value of the total DOS at the Fermi level is 3.64 states $/ \mathrm{eV}$ for $\mathrm{AlZr}_{3}$. The value of the total DOS at the Fermi level is 5.74 states $/ \mathrm{eV}$ for $\mathrm{AlCu}_{2} \mathrm{Zr}$. Therefore, $\mathrm{AlZr}_{3}$ has a more stable structure in these three Al-based intermetallics. This accorded with the calculation of cohesive energy. 
From Fig. 1, one can also see that the pseudogap or quasigap near the Fermi energy is the broadest for $\mathrm{AlZr}_{3}$, and the narrowest for $\mathrm{AlCu}_{2} \mathrm{Zr}$, which suggests that $\mathrm{AlZr}_{3}$ has the strongest covalent bond, $\mathrm{AlCu}_{3}$ has an intermediate covalent bond, while $\mathrm{AlCu}_{2} \mathrm{Zr}$ has the worst covalent bond, i.e., $\mathrm{AlZr}_{3}$ may have the worst ductility among these three Al-based intermetallics, $\mathrm{AlCu}_{3}$ has an intermediate ductility, while $\mathrm{AlCu}_{2} \mathrm{Zr}$ has most ductility.

According to the partial DOS, the large occupied peak for the $\mathrm{AlCu}_{3}, \mathrm{AlCu}_{2} \mathrm{Zr}, \mathrm{AlZr}_{3}$ alloys is dominated by $\mathrm{Al} 3 s$ and $3 p$ states, $\mathrm{Cu} 3 d$ states, $\mathrm{Zr} 5 s$ and $4 d$ states, respectively. In the valence band range, there is hybridization in these alloys, and $\mathrm{AlZr}_{3}$ has the strongest hybridization in these three Al-based intermetallics. This is an advantage for ductility of $\mathrm{AlZr}_{3}$ alloy. However, from the above analysis, it can be seen that the pseudogap or quasigap near the Fermi energy for $\mathrm{AlZr}_{3}$ is the broadest among these Al-based alloys. This is a disadvantage for ductility of $\mathrm{AlZr}_{3}$. Thus, the ductility of $\mathrm{AlZr}_{3}$ alloy may be less than that of $\mathrm{AlCu}_{3}$ and $\mathrm{AlCu}_{2} \mathrm{Zr}$ alloys.

\section{Conclusions}

In summary, using the first-principles method we have calculated alloying stability, electronic structure, and mechanical properties of Al-based intermetallic compounds $\left(\mathrm{AlCu}_{3}, \mathrm{AlCu}_{2} \mathrm{Zr}\right.$, and $\left.\mathrm{AlZr}_{3}\right)$. The calculation of cohesive energies showed that the structural stability of these Al-based intermetallics will become higher with increasing $\mathrm{Zr}$ element in crystal. The calculation of formation energies showed that the alloying ability of $\mathrm{AlCu}_{2} \mathrm{Zr}$ is strongest. $\mathrm{AlCu}_{2} \mathrm{Zr}$ can exhibit a good ductility, followed by $\mathrm{AlCu}_{3}$, whereas $\mathrm{AlZr}_{3}$ can have a poor ductility; however, for stiffness, these intermetallics show a converse order. In particular, $\mathrm{AlCu}_{3}$ is much more anisotropic than the other two intermetallics. The valence bonds of these intermetallics are attributed to the valence electrons of $\mathrm{Cu} 3 d$ states for $\mathrm{AlCu}_{3}, \mathrm{Cu} 3 d$, and $\mathrm{Zr} 4 d$ states for $\mathrm{AlCu}_{2} \mathrm{Zr}$, and $\mathrm{Al} 3 s, \mathrm{Zr} 5 s$ and $4 d$ states for $\mathrm{AlZr}_{3}$, respectively, and the electronic structure of the $\mathrm{AlZr}_{3}$ shows the strongest hybridization, leading to the worst ductility.

\section{References}

[1] G. Sauthoff, in: Intermetallic Compounds, Eds. J.H. Westbrook, R.L. Fleischer, Vol. 1, Wiley, New York 1994, p. 991.

[2] R.W. Cahn, Intermetallics 6, 563 (1998).

[3] P.K. Rajagopalan, I.G. Sharma, T.S. Krishnan, J. Alloys Comp. 285, 212 (1999).

[4] P. Wonwook, Mater. Design 17, 85 (1996).

[5] W. Zhou, L.J. Liu, B.L. Li, Q.G. Song, P.J. Wu, Electron Mater. 38, 356 (2009).

[6] C. Emmanuel, J.M. Sanchez, Phys. Rev. B 65, 094105 (2002).
[7] G. Ghosh, M. Asta, Acta Mater. 53, 3225 (2005).

[8] G. Ghosh, Acta Mater. 55, 3347 (2007).

[9] W.J. Ma, Y.R. Wang, B.C. Wei, Y.F. Sun, Trans. Nonferrous Met. Soc. China 17, 929 (2007).

[10] S. Pauly, J. Das, N. Mattern, D.H. Kim, J. Eckert, Intermetallics 17, 453 (2009).

[11] H. Baltache, R. Khenata, M. Sahnoun, M. Driz, B. Abbar, B. Bouhafs, Physica B 344, 334 (2004).

[12] G. Kresse, J. Hafner, Phys. Rev. B 49, 14251 (1994).

[13] G. Kresse, J. Furthmüller, Phys. Rev. B 54, 11169 (1996).

[14] W. Kohn, L.J. Sham, Phys. Rev. 140, A1133 (1965).

[15] J.P. Perdew, Y. Wang, Phys. Rev. B 45, 13244 (1992).

[16] P.E. Blöchl, Phys. Rev. B 50, 17953 (1994).

[17] H.J. Monkhorst, J.D. Pack, Phys. Rev. B 13, 5188 (1976).

[18] P.E. Blöchl, O. Jepsen, O.K. Andersen, Phys. Rev. B 49, 16223 (1994)

[19] M. Draissia, M.Y. Debili, N. Boukhris, M. Zadam, S. Lallouche, Copper 10, 65 (2007).

[20] W.J. Meng, J. Faber, Jr., P.R. Okamoto, L.E. Rehn, B.J. Kestel, R.L. Hitterman, J. Appl. Phys. 67, 1312 (1990).

[21] R. Meyer zu Reckendorf, P.C. Schmidt, A. Weiss, Z. Phys. Chem. N.F. 163, 103 (1989).

[22] F.J. Birch, Geophys. Res. 83, 1257 (1978).

[23] V.I. Zubov, N.P. Tretiakov, J.N. Teixeira Rabelo, Phys. Lett. A 194, 223 (1994).

[24] M. Mattesini, R. Ahuja, B. Johansson, Phys. Rev. B 68, 184108 (2003).

[25] W.Y. Yu, N. Wang, X.B. Xiao, B.Y. Tang, L.M. Peng, W.J. Ding, Solid State Sci. 11, 1400 (2009).

[26] B.Y. Tang, N. Wang, W.Y. Yu, X.Q. Zeng, W.J. Ding, Acta Mater. 56, 3353 (2008).

[27] H.M. Ledbetter, J. Appl. Phys. 44, 1451 (1973).

[28] A. Taga, L. Vitos, B. Johansson, G. Grimvall, Phys. Rev. B 71, 014201 (2005).

[29] S.F. Pugh, Philos. Mag. 45, 823 (1954).

[30] V. Tvergaard, J.W. Hutchinson, J. Am. Ceram. Soc. 71, 157 (1988).

[31] B.B. Karki, L. Stixrude, S.J. Clark, M.C. Warren, G.J. Ackland, J. Crain, Am. Miner. 82, 51 (1997).

[32] P. Chen, D.L. Li, J.X. Yi, W. Li, B.Y. Tang, L.M. Peng, et al., Solid State Sci. 11, 2156 (2009).

[33] J.H. Xu, W. Lin, A.J. Freeman, Phys. Rev. B 48 , 4276 (1993).

[34] J.H. Xu, T. Oguchi, A.J. Freeman, Phys. Rev. B 36, 4186 (1987).

[35] T. Hong, T.J. Watson-Yang, A.J. Freeman, T. Oguchi, J.H. Xu, Phys. Rev. B 41, 12462 (1990). 